\title{
THE EFFECT OF BRASS (Cu-Zn) CATALYTIC CONVERTER MUFFLER ON ENGINE PERFORMANCE
}

\author{
EllyANIE $^{1 *}$, DeVAN OKTABRI H ${ }^{1}$ \\ ${ }^{1}$ Department of Mechanical Engineering, Faculty of Engineering, Universitas Sriwijaya, Indralaya, \\ 30662, Sumatera Selatan, Indonesia \\ *Corresponding author: ellyanie@ unsri.ac.id
}

(Received: 15 March 2021; Accepted: 25 May 2021; Published on-line: 1 July 2021)

\begin{abstract}
Installing a catalytic converter in the muffler is a typical method of reducing engine exhaust emissions. Catalytic converters have been shown to lower exhaust pollutants while enhancing engine performance. The influence of the number of brass catalyst plates $(\mathrm{Cu}-\mathrm{Zn})$ on the Performance of the four stroke commercial Yamaha Jupiter MX motorcycle engine manufactured in 2007 was investigated in this study. The catalyst is installed in the motorbike muffler, with the number of catalyst plates varying between 5 and 8 , and a conventional uncatalyzed muffler serving as a comparison. Torque, power, specific fuel consumption, and thermal efficiency are among the performance factors that will be considered. A prony brake dynamometer was used to conduct torque and power measurements. The results indicate that exhaust with eight catalyst plates can improve engine performance more than an exhaust with five catalyst plates. Furthermore, mufflers equipped with eight catalyst plates can boost engine efficiency by an average of $17.65 \%$. Thus, increasing the number of catalyst brass plates improves the machine's efficiency.
\end{abstract}

KEY WORDS: Engine, catalytic, converter, performance

\section{INTRODUCTION}

The increase in motorized vehicle use corresponds to the growing number of people who rely on these daily activities [1]. The high amount of air pollution induced by machine use is unavoidable and is particularly prevalent in developing nations such as Indonesia [2]. The most excellent significant source of air pollution is exhaust emissions from motor vehicle combustion [3]. Installing a catalytic converter is one approach to minimize exhaust emissions. A catalytic converter can lower exhaust emissions by assisting or speeding up the process of converting a substance, although the catalyst element itself does not react [4]. Installing a catalytic converter accelerates the oxidation of hydrocarbon and carbon monoxide emissions, as well as the NOx reduction reaction [5].

Typically, the catalytic converter is mounted in the muffler system of the car. However, consider the insertion of a catalytic converter to retain engine performance. Numerous studies have been undertaken to determine the effect of installing a catalytic converter on a vehicle's engine [6]. According to Manunggal and Warju [7], the installation of a copper-based catalytic converter in the muffler will reduce exhaust emissions and increase torque by $25.96 \%$ and power by $25.54 \%$. Meanwhile, Amboro and Warju [8] researched the effect of thick metallic catalytic converter plates made of nickel-plated brass to reduce $\mathrm{CO}$ and $\mathrm{HC}$ emissions and improve engine performance.

Catalytic converters have been used to reduce exhaust emissions from motor vehicles for an extended period. Since 1975, this device has been utilized in the United States of America 
(USA) to comply with increasingly strict environmental protection agency (EPA) requirements addressing motor vehicle exhaust gases. This technology degrades or eliminates hazardous chemicals (poisons) in exhaust gases $[9,10]$.

The increase in air pollution caused by transportation modes hugely concerns and negatively influences life and the environment in the modern-day. Carbon monoxide (CO), hydrocarbons ( $\mathrm{HC})$, nitrogen oxides (NOx), sulfur oxides ( $\mathrm{SO} 2)$, and lead $(\mathrm{Pb})$ can all be produced by a vehicle $[11,12]$. The most prevalent of these poisons is Carbon Monoxide gas, which is created during inefficient fuel combustion and is used in gasoline engines [13].

Carbon monoxide gas is produced during lean combustion as a result of insufficient mixing of fuel and air. One may say that the $\mathrm{CO}$ setting is extremely low in terms of the proportion of fuel entering the combustion chamber. Agree with the hypothesis; if the amount of oxygen in the mixture exceeds the degree of the complete circle mixture (hypothesis), the mixture will also become tilted, preventing the formation of $\mathrm{CO}$. However, $\mathrm{CO}$ does occur and is routed throughout the mix for slanted boot. After all, this is a carefully orchestrated response.

A catalyst converter is a term that refers to a catalyst that is installed in the space immediately behind the muffler duct. Its purpose is to filter hydrocarbons (unburned gasoline) and other engine contaminants. When platinum and palladium materials are used, catalysts are quite expensive [14].

It is anticipated that this research will enable the development of an alternate solution to the problem of air pollution caused by motorcycle exhaust emissions without compromising the engine's Performance through the use of a low-cost catalytic converter put in the muffler.

\section{MATERIAL AND METHOD}

This research entails numerous procedures; the following is a flow chart outlining each one (Fig. 1).

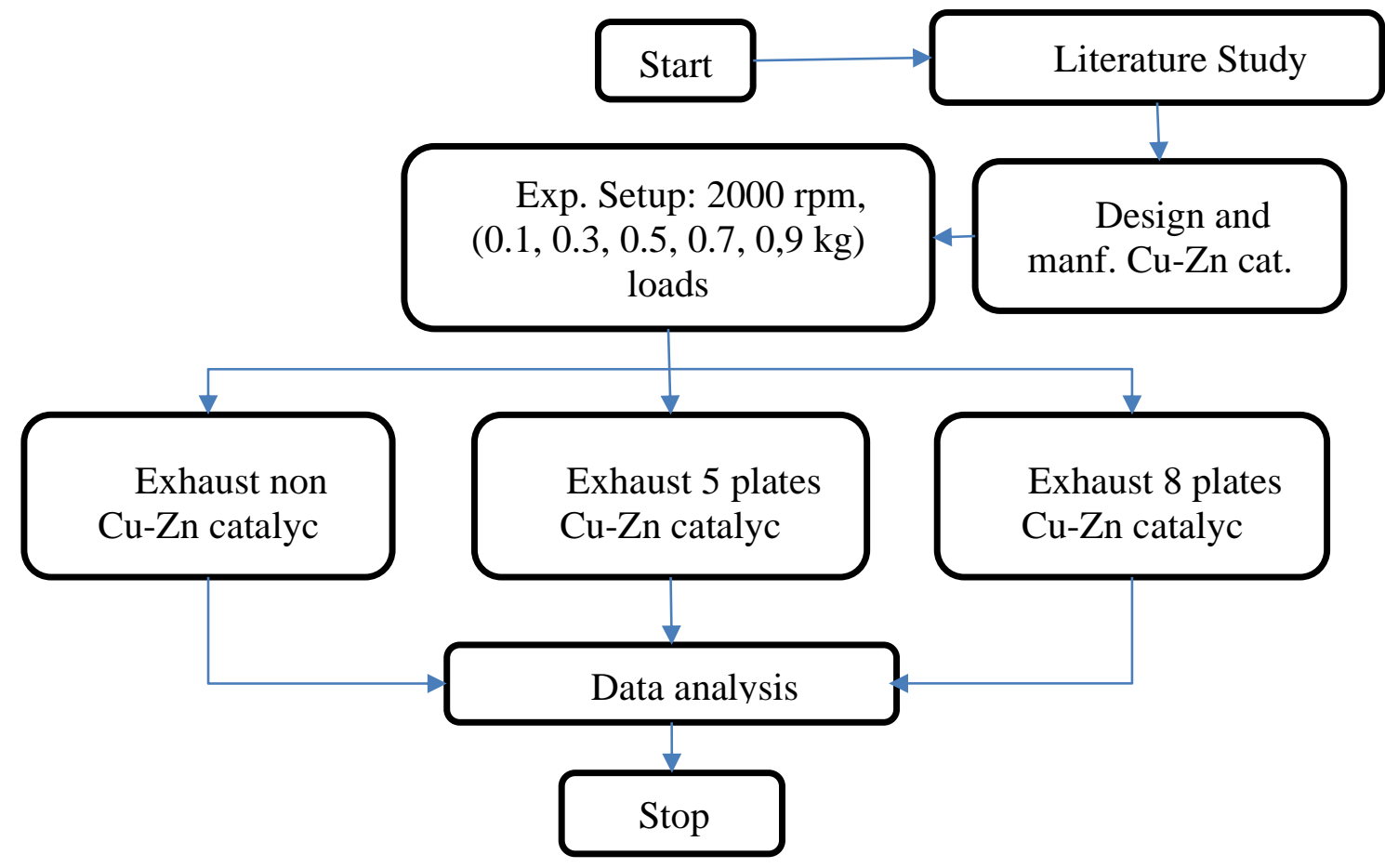

Fig. 1. Research procedure 
https://doi.org/10.51630/ijes.v2i2.20

The investigation was conducted experimentally on a four-stroke gasoline-powered combustion engine of the YAMAHA brand type Jupiter MX built in 2007. The first step was to place a digital tachometer on the motor to monitor the engine speed. Then comes the design and construction of the catalytic converter that will be inserted in the muffler. The next stage is performance testing utilizing a Prony brake dynamometer to determine torque and power.

Table 1: Jupiter MX motorcycle specifications

\begin{tabular}{cc|cc}
\hline \multicolumn{2}{c|}{ Dimensions and weight } & \multicolumn{2}{c}{ Engine Type } \\
\hline Length & $1945 \mathrm{~mm}$ & Engine & Four-stroke \\
Width & $705 \mathrm{~mm}$ & Number of cylinders & 1 cylinder \\
Height & $1065 \mathrm{~mm}$ & Fuel & Ron 92 \\
Piston stroke & $58.7 \mathrm{~mm}$ & Compression ratio & $10.9: 1$ \\
Cylinder volume & $135 \mathrm{cc}$ & Maximum power & $8.45 \mathrm{~kW}$ at $8500 \mathrm{rpm}$ \\
Cylinder diameter & $54.0 \mathrm{~mm}$ & Maximum torque & $11.65 \mathrm{Nm}$ at $5500 \mathrm{rpm}$ \\
\hline
\end{tabular}

A brass $(\mathrm{Cu}-\mathrm{Zn})$ catalytic converter was used in this investigation, as seen in Fig. 2. The catalyst's cross-section is shaped like a circle with a diameter of $90 \mathrm{~mm}$ and a plate thickness of $1 \mathrm{~mm}$. The catalyst part was perforated with up to 21 holes, a diameter of $8 \mathrm{~mm}$ and a spacing of $15 \mathrm{~mm}$ between holes.

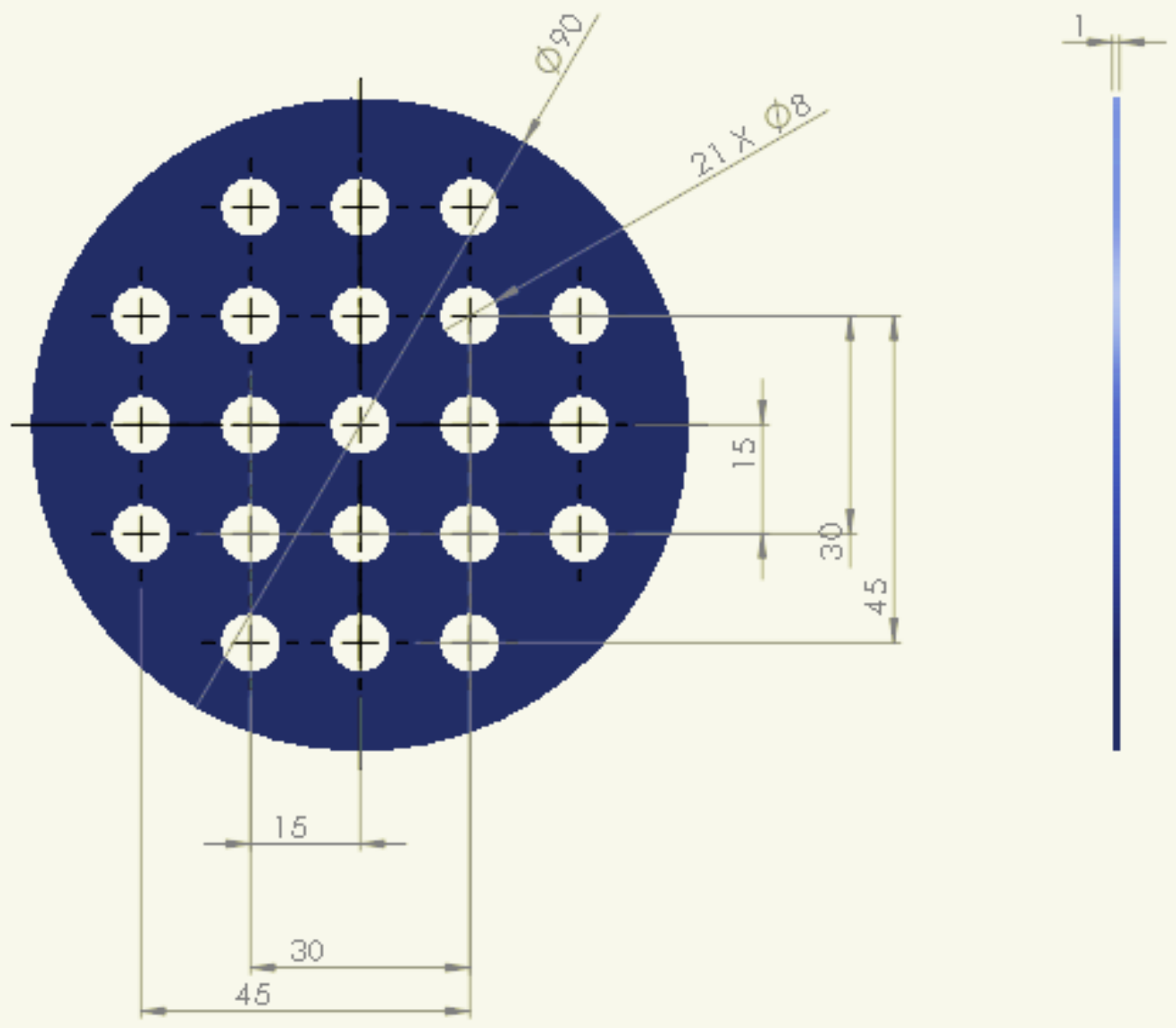

Fig. 2. Details of the catalyst design (unit in $\mathrm{mm}$ )

The prepared catalyst is next positioned in the typical motor exhaust section (Fig. 3), with the number of catalyst plates varying between five and eight as shown at Fig. 4 and 5. The plates are $3 \mathrm{~mm}$ apart. Three test mufflers were employed in the investigation. 


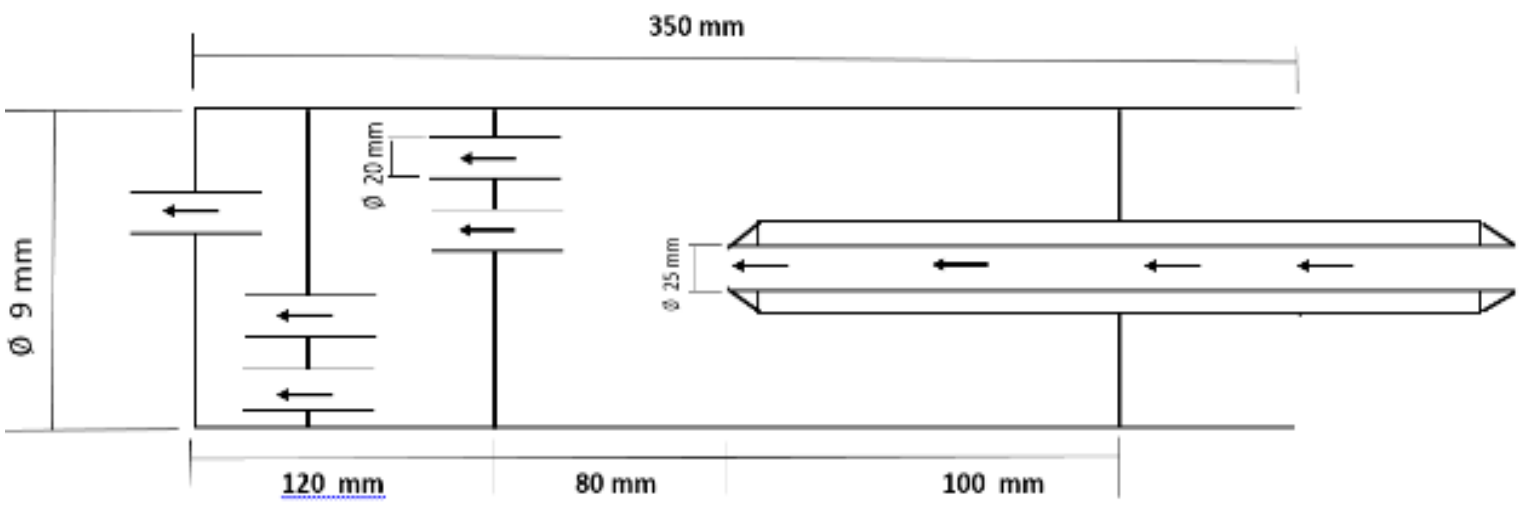

Fig. 3. Standard exhaust schematic

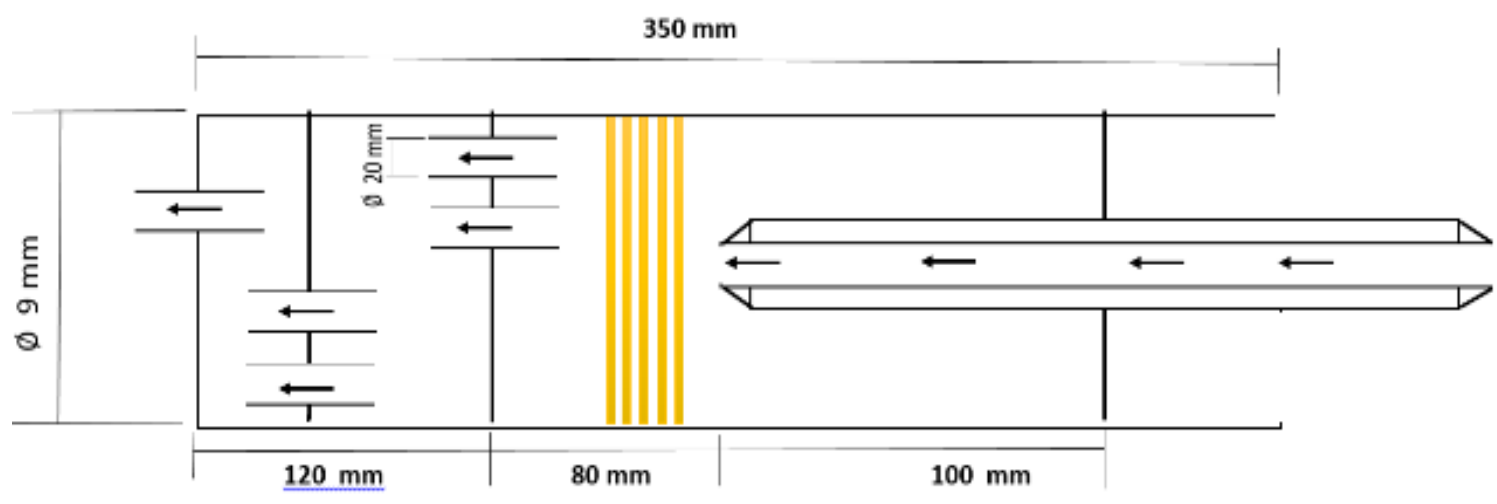

Fig. 4. Schematic of exhaust with catalyst 5 plate

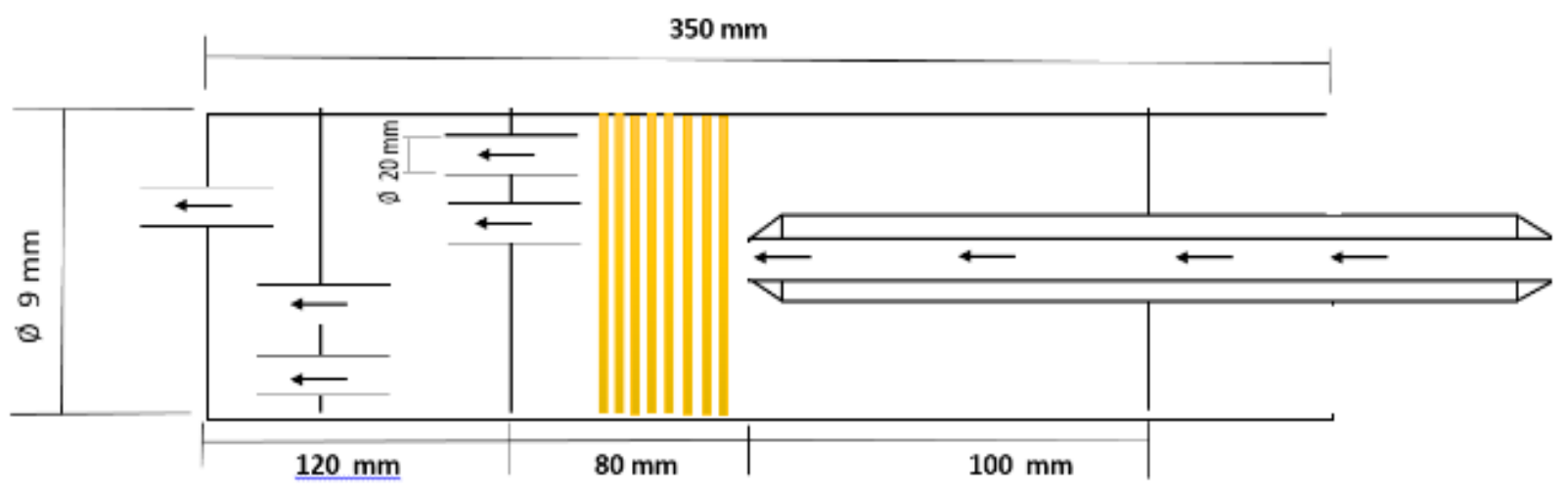

Fig. 5. Schematic of exhaust with catalyst eight plate

The prony brake dynamometer utilized in this investigation is the result of its design and installation. The prony brake testing equipment design entails creating the prony brake's dimensions and construction using the solid works 2014 application. Fig. 6.a and b illustrate the prony brake test tool's schematic.

Three types of muffler were employed in this test: conventional muffler, muffler with an additional five catalyst plates, and muffler with an additional eight catalyst plates. The test is conducted with the factors under consideration such as constant engine speed at $2000 \mathrm{rpm}$ and 
load fluctuations $(0.1 \mathrm{~kg} ; 0.3 \mathrm{~kg} ; 0.5 \mathrm{~kg} ; 0.7 \mathrm{~kg} ; 0.9 \mathrm{~kg})$. Torque and power measurements was be made with a Prony brake dynamometer, as seen in Fig. 6. Test was endded when $5 \mathrm{ml}$ of fuel consumed.

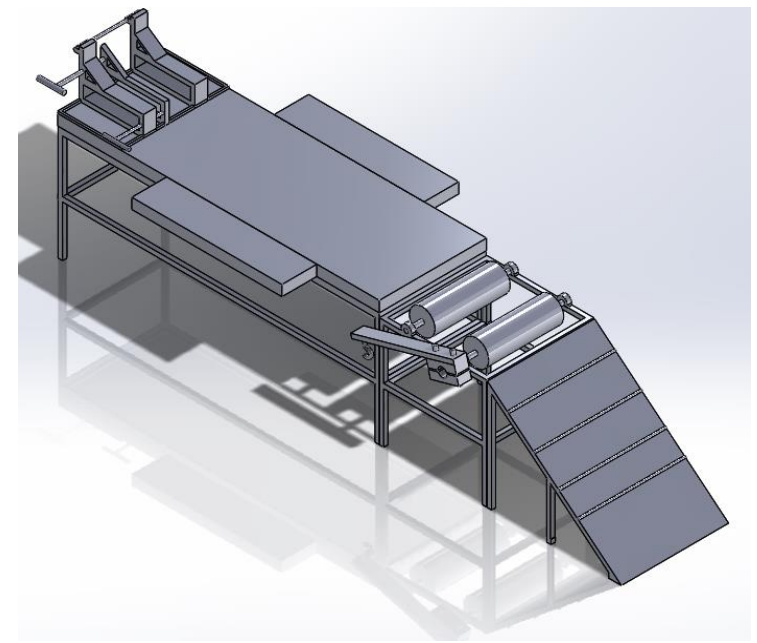

$\mathrm{a}$

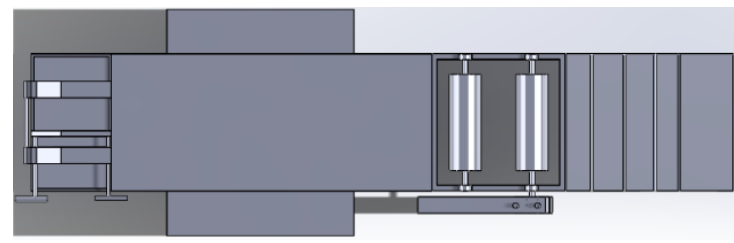

b

Fig. 6. Schematic of the prony brake test; isometric (a) and top view (b)

\section{RESULT AND DISCUSSION}

As illustrated in Fig. 7, at a constant engine speed of 2000 rpm, the higher the load, the higher the fuel consumption. In other words, using a brass catalytic converter can help you save money on fuel.

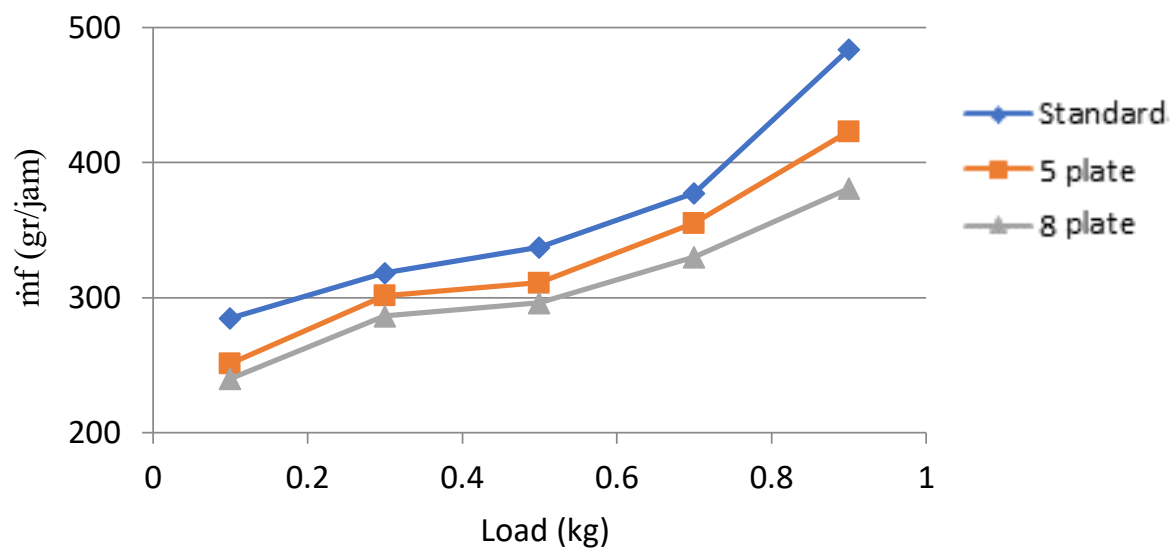

Fig. 7. Comparison graph of fuel consumption rate

The most significant reduction in fuel consumption occurred with a Prony load of $0.9 \mathrm{~kg}$, or 12.56 percent. While the slightest reduction in fuel usage came at a load of $0.3 \mathrm{~kg}$, a 5.25 percent reduction. If the average value is used, the percentage reduction in fuel consumption in the muffler is 8.84 percent with five catalyst plates.

By increasing the number of catalyst plates in the muffler to eight, the engine's fuel consumption is further reduced. The most significant reduction in emissions with eight catalyst 
plates was 21.30 percent at $0.9 \mathrm{~kg}$ Prony load. At the same time, the smallest reduction in fuel usage came at a weight of $0.3 \mathrm{~kg}$, a 10.03 percent reduction. Thus, with eight catalyst plates, the average percentage reduction in fuel consumption in the muffler is 14.89 percent.

According to the statistics presented, the most significant reduction in fuel consumption occurs in the muffler with eight catalyst plates. This demonstrates that increasing the number of catalyst plates utilized will result in an additional reduction in fuel use.

The influence of load on fuel consumption is depicted in Fig. 8. The higher the strain on the prony brake, the less fuel the engine needs to generate power per unit time. The specific fuel consumption value is a measure of an engine's efficiency. The lower the specific fuel consumption of an engine, the more efficiently it burns gasoline. Utilizing a brass catalytic converter in the muffler system can result in a reduction in particular fuel consumption.

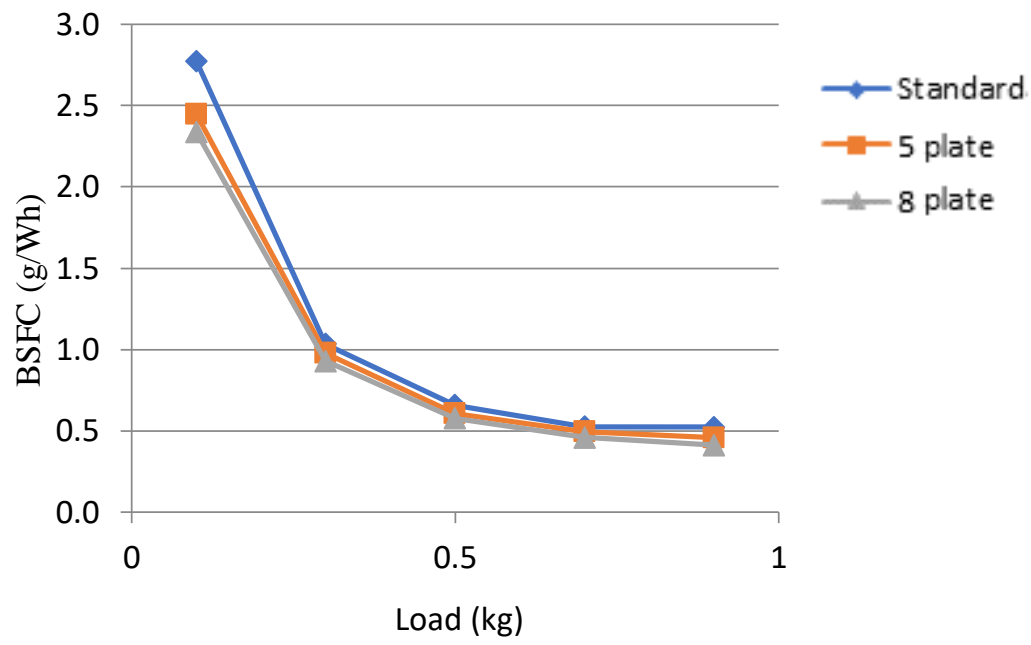

Fig. 8. Comparison of brake-specific fuel consumption

With five catalyst plates, the highest specific fuel consumption in the muffler occurs at a weight of $0.1 \mathrm{~kg}$, or $2.44 \mathrm{~g} / \mathrm{Wh}$. Conversely, the lowest specific fuel consumption in the muffler with five catalyst plates was $0.46 \mathrm{~g} / \mathrm{Wh}$ at a load of $0.9 \mathrm{~kg}$. With five catalyst plates, the average specific fuel consumption in the muffler is $0.99 \mathrm{~g} / \mathrm{Wh}$. Thus, with five catalyst plates, the average specific fuel consumption in the muffler is reduced by 9.59 percent.

The engine with eight catalyst plate muffler consumes the most fuel at $0.1 \mathrm{~kg}$ Prony load or $2.33 \mathrm{~g} / \mathrm{Wh}$. At the same time, the particular fuel usage was lowest at $0.9 \mathrm{~kg}$, at $0.41 \mathrm{~g} / \mathrm{Wh}$. With eight catalyst plates, the average specific fuel consumption in the muffler is $0.94 \mathrm{~g} / \mathrm{Wh}$. Therefore, the average percentage reduction in fuel usage in muffler from vehicles equipped with eight catalyst plates is 14.47 percent.

According to the graph in Fig. 6. The muffler with eight catalyst plates has the most significant reduction in specific fuel consumption. This is because the backpressure effect of an engine equipped with an eight-plate catalytic muffler is higher than the effect of an engine equipped with a five-plate catalytic muffler and a conventional muffler. Although the backpressure effect is negligible, it can affect a machine's Performance. The effect of backpressure on eight catalyst plates is higher than the effect on five catalyst plates in the standard.

Backpressure will force air into the combustion chamber. The catalyst muffler with eight plates has the greatest backpressure impact, as more plates increase the resistance in the muffler gases. As a result, when the intake and muffler valves overlap, some of the air and fuel mixture 
entering the combustion chamber is pushed back into the intake valve. As a result, the mixture of fuel and air entering the combustion chamber is reduced.

By increasing the number of catalyst plates, the backpressure effect can be enhanced, resulting in a reduction in fuel consumption and an increase in engine efficiency.

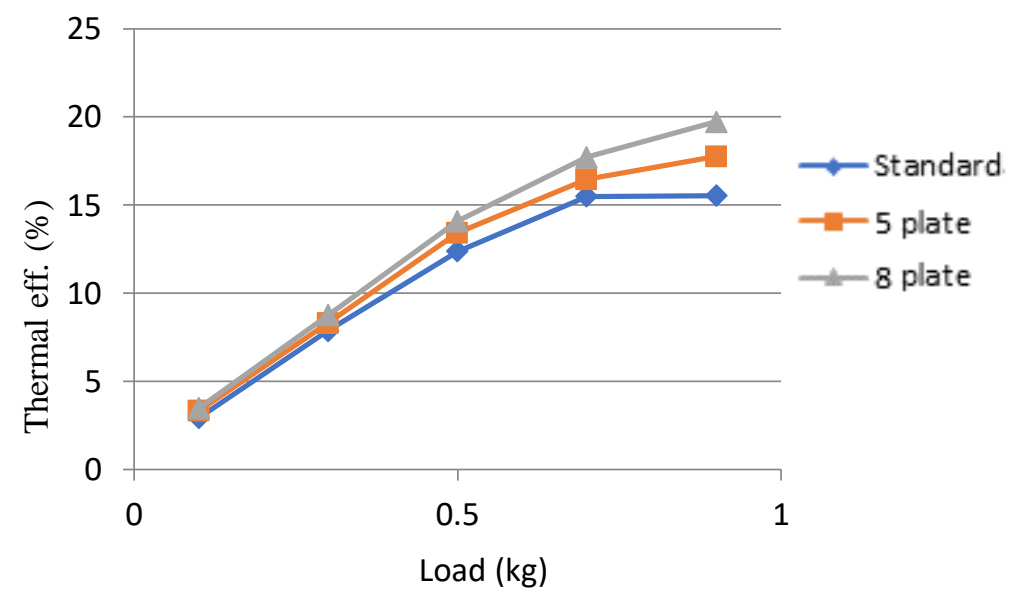

Fig. 9. Thermal Efficiency Comparison

Fig. 9 demonstrates that the higher the load on the prony brake, the more efficient the 2007 Yamaha Jupiter MX motorbike engine's thermal efficiency. The higher an engine's thermal efficiency, the better its Performance.

The 2007 Yamaha Jupiter MX motorbike exhaust can benefit from the addition of a brass catalytic converter. Thermal efficiency increased when the standard muffler was modified by increasing the number of catalyst plates.

The best thermal efficiency in the muffler with five catalyst plates is 17.76 percent, with a load of $0.9 \mathrm{~kg}$. The thermal efficiency of the muffler with five catalyst plates is lowest at 0.1 kilograms or 3.32 percent. When the thermal efficiency of the conventional muffler is compared to that of the 5-catalyst muffler, there is an increase. At a load of $0.9 \mathrm{~kg}$, the largest increase in thermal efficiency in the muffler with five catalyst plates over the ordinary muffler was 14.36 percent. At the same time, the smallest percentage gain occurs at $0.3 \mathrm{~kg}$, at 5.53 percent. If the average value is used, the thermal efficiency of the muffler with five catalyst plates is increased by 9.34 percent when compared to the conventional muffler.

The best thermal efficiency in the muffler with eight catalyst plates is 19.74 percent with a load of $0.9 \mathrm{~kg}$, while the lowest thermal efficiency is 3.48 percent at a load of $0.1 \mathrm{~kg}$. At a load of $0.9 \mathrm{~kg}$, the largest increase in thermal efficiency of the muffler with eight catalyst plates over the standard muffler was 27.06 percent. Meanwhile, the lowest percentage rise was 11.14 percent at $0.3 \mathrm{~kg}$ load. If the average value is used, the thermal efficiency of the muffler with eight catalyst plates is increased by 17.65 percent compared to the conventional muffler.

Increased engine performance can be achieved by increasing the number of catalyst plates in the 2007 Yamaha Jupiter MX motorbike muffler. Increased thermal efficiency is associated with an increase in the number of catalyst plates. In addition, the more catalyst plates there are, the higher the backpressure effect on the muffler.

If the influence of backpressure performance exceeds the prescribed limit, a return to the combustion chamber occurs, reducing the efficacy of the muffler gas exiting the combustion chamber. Then some exhaust gas will be reintroduced into the combustion chamber. The worstcase scenario is that exhaust gases can enter the intake valve in an overwhelming amount during 
overlapping. As a result, the fresh air will become contaminated with unburnable exhaust gases. As a result, engine performance and the effect of engine damage will diminish.

Excessive or insufficient backpressure has a detrimental influence on engine performance. This demonstrates that the rise in back pressure caused by adding the catalyst plates utilized in this investigation remains below acceptable limits as a result of increased engine performance.

\section{CONCLUSION REMARKS}

The conclusions of this study are:

1. When the load was added to the 2007 Yamaha Jupiter MX motorbike engine, torque and axle power increased.

2. Exhaust with five catalyst plates may save an average of 8.84 percent on fuel consumption, while exhaust with eight catalyst plates can save an average of 14.89 percent on fuel consumption.

3. Exhaust with five catalyst plates may average a 9.59 percent reduction in specific fuel consumption, while exhaust with eight catalyst plates can average a 14.47 percent reduction in specific fuel consumption.

4. Exhaust with five catalyst plates improves the thermal efficiency of the engine by an average of 9.34 percent. In contrast, exhaust with eight catalyst plates improves the thermal efficiency of the engine by an average of 17.65 percent.

5. According to engine performance testing, adding a brass $(\mathrm{Cu}-\mathrm{Zn})$ catalytic converter to the exhaust can boost engine performance. However, the number of plates on the catalyst affects the improvement in Performance. This is because the more plates there are, the higher the resultant back pressure.

\section{REFERENCES}

[1] V. Ganesan, Internal Combustion Engines, Third. ed. ed. New Delhi: McGraw Hill, 2012.

[2] BPS. (13 January 2018). Growth in the Number of Motorized Vehicles by Type, 1949-2018. Available: https://www.bps.go.id/linkTableDinamis/view/id/1133

[3] C. N. Grimaldi and F. Millo, "Internal Combustion Engine (ICE) Fundamentals," in Handbook of Clean Energy Systems, 2015, pp. 1-32.

[4] C. Ozhan, "Multi-scale simulation of automotive catalytic converters," Université Pierre et Marie Curie - Paris VI, 2014PA066484, 2014.

[5] A. Chafidz, Megawati, C. R. Widyastuti, V. Augustia, K. Nisa, and Ratnaningrum, "Application of copper-zinc metal as a catalytic converter in the motorcycle muffler to reduce the exhaust emissions," IOP Conference Series: Earth and Environmental Science, vol. 167, 2018.

[6] S. P. Venkatesan, D. S. Uday, B. K. Hemant, K. R. Kushwanth Goud, G. L. Kumar, and K. P. Kumar, "I.C. Engine emission reduction by copper oxide catalytic converter," IOP Conference Series: Materials Science and Engineering, vol. 197, 2017.

[7] R. Manunggal and Warju, "The Effect Of The Use Of Copper Metallic Catalytic Converter And Sass Technology Applications On The Performance Of Honda New Mega Pro Motorcycles," (in Indonesia), Jurnal Teknik Mesin, FT Unesa, vol. 01, no. 02, pp. 110-115, 2013.

[8] E. W. Amboro and Warju, "The Effect Of The Use Of Brass Metallic Catalytic Converter And Sass Technology Applications On Motorcycle Emissions Honda New Mega Pro," (in Indonesia), Jurnal Teknik Mesin, FT Unesa, vol. 01, no. 02, pp. 102-109, 2013.

[9] W. Zhou et al., "New horizon in $\mathrm{C} 1$ chemistry: breaking the selectivity limitation in transformation of syngas and hydrogenation of $\mathrm{CO} 2$ into hydrocarbon chemicals and fuels," Chem Soc Rev, vol. 48, no. 12, pp. 3193-3228, Jun 172019. 
[10] S. R. H. Barrett et al., "Impact of the Volkswagen emissions control defeat device on US public health," Environmental Research Letters, vol. 10, no. 11, 2015.

[11] S. Kattel, P. J. Ramirez, J. G. Chen, J. A. Rodriguez, and P. Liu, "Active sites for CO2 hydrogenation to methanol on $\mathrm{Cu} / \mathrm{ZnO}$ catalysts," Science, vol. 355, no. 6331, pp. 1296-1299, Mar 242017.

[12] Y. Jiang et al., "Slurry methanol synthesis from $\mathrm{CO} 2$ hydrogenation over micro-spherical $\mathrm{SiO} 2$ support $\mathrm{Cu} / \mathrm{ZnO}$ catalysts," Journal of CO2 Utilization, vol. 26, pp. 642-651, 2018.

[13] S. Kuld et al., "Quantifying the promotion of $\mathrm{Cu}$ catalysts by $\mathrm{ZnO}$ for methanol synthesis," Science, vol. 352, no. 6288, pp. 969-74, May 202016.

[14] N. R. C. U. C. S. Roundtable, "Replacing Critical Materials with Abundant Materials," in The Role of the Chemical Sciences in Finding Alternatives to Critical Resources: A Workshop SummaryWashington (DC): National Academies Press (US), 2012. 